Document downloaded from:

http://hdl.handle.net/10251/80982

This paper must be cited as:

Serrano Cruz, JR.; Arnau Martínez, FJ.; García-Cuevas González, LM.; Dombrovsky, A.; Tartoussi, H. (2016). Development and validation of a radial turbine efficiency and mass flow model at design and off-design conditions. Energy Conversion and Management. 128:281293. doi:10.1016/j.enconman.2016.09.032.

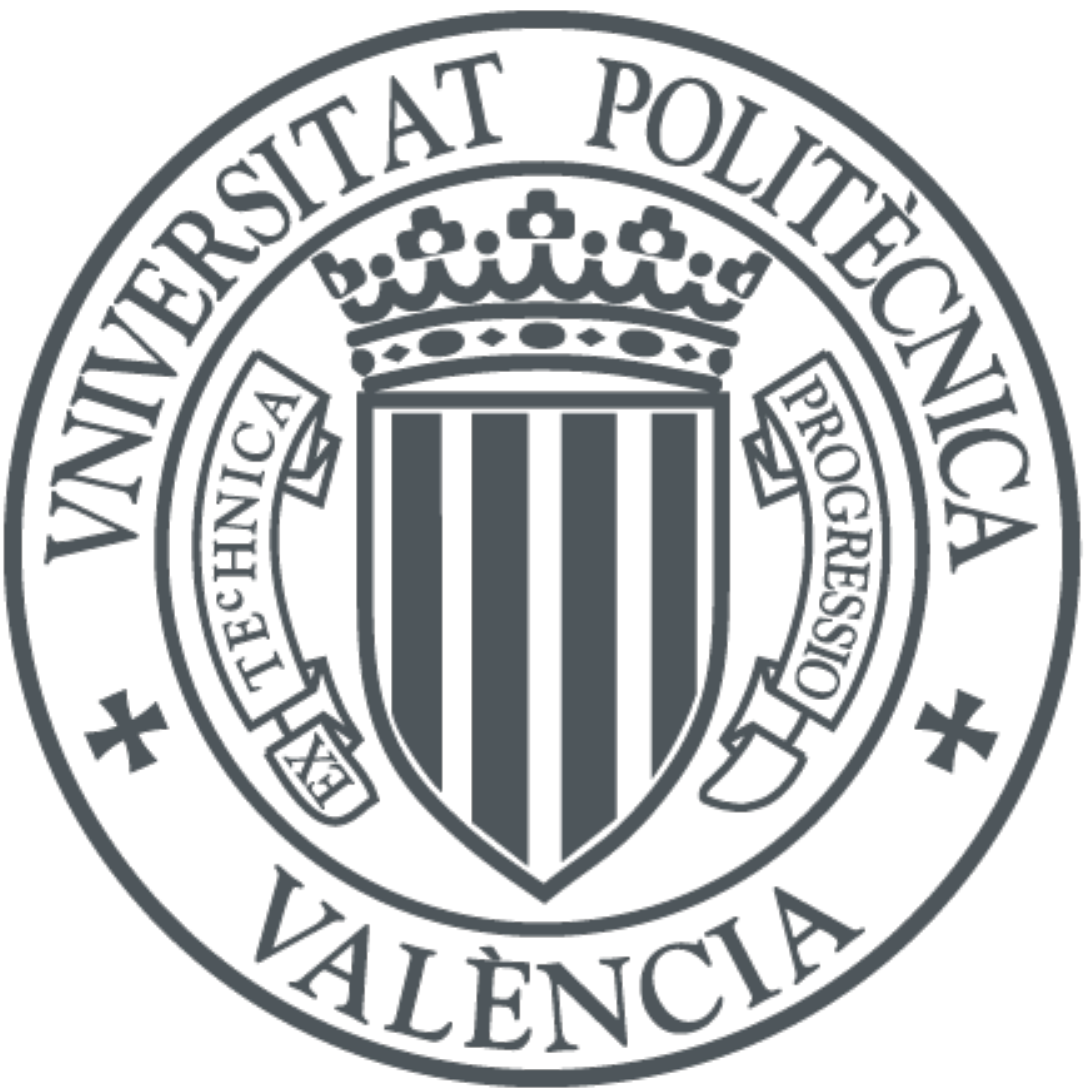

The final publication is available at

http://dx.doi.org/10.1016/j.enconman.2016.09.032

Copyright Elsevier

Additional Information 


\title{
Development and validation of a radial turbine efficiency and mass flow model at design and off-design conditions
}

\author{
José Ramón Serrano ${ }^{\mathrm{a}}$, Francisco José Arnau ${ }^{\mathrm{a}, *}$, Luis Miguel García-Cuevas ${ }^{\mathrm{a}}$, \\ Artem Dombrovsky ${ }^{\mathrm{a}}$, Hadi Tartoussi ${ }^{\mathrm{b}}$ \\ ${ }^{a}$ CMT-Motores Térmicos, Universitat Politècnica de València, Valencia 46022, Spain. \\ ${ }^{b}$ Renault S.A.S., Powertrain Division, Centre Technique de Lardy, France
}

\begin{abstract}
Turbine performance at extreme off-design conditions is growing in importance for properly computing turbocharged reciprocating internal combustion engines behaviour during urban driving conditions at current and future homologation cycles. In these cases, the turbine operates at very low flow rates and power outputs and at very high blade to jet speed ratios during transitory periods due to turbocharger wheel inertia and the high pulsation level of engine exhaust flow. This paper presents a physically based method that is able to extrapolate radial turbines reduced mass flow and adiabatic efficiency in blade speed ratio, turbine rotational speed and stator vanes position. The model uses a very narrow range of experimental data from turbine maps to fit the necessary coefficients. By using a special experimental turbocharger gas stand, experimental data have been obtained for extremely low turbine power outputs for the sake of model validation. Even if the data used for fitting only covers the turbine normal operation zone, the extrapolation model provides very good agreement with the experiments at very high blade speed ratio points; producing also good results when extrapolating in rotational speed and stator vanes position.
\end{abstract}

Keywords: Turbocharger, Adiabatic efficiency extrapolation, Mean-line

\footnotetext{
${ }^{*}$ Corresponding author. Tel: +34963877650 ; fax: +34963877659

Email address: farnau@mot.upv.es (Francisco José Arnau)

$U R L$ : www.cmt.upv.es (Francisco José Arnau)
} 
model, Radial turbine simulation, Off-design, High blade to jet speed ratio

\section{Acronyms}

VGT Variable geometry turbine

FGT Fixed geometry turbine

ICE Internal combustion engine

\section{Nomenclature}

$A$

$a$

$b$

$c$

$C_{D}$

$c_{s s}$

$c_{p}$

$D$

$d$

K

$L$

$\dot{m}$

$\dot{m}_{\text {red }}$

$n$

$n_{\text {red }}$

$n_{b}$

$p$

$R$

$r$

$s d$
Area $\left(m^{2}\right)$

Rotor discharge coefficient (-)

Reduced mass flow fitting coefficient (-)

Reduced mass flow fitting coefficient (-)

Discharge coefficient (-)

Isentropic jet velocity $\left(\mathrm{ms}^{-1}\right)$

Specific heat capacity at constant pressure

$\left(J K^{-1}\right)$

Diameter $(m)$

Reduced mass flow fitting coefficient (-)

Efficiency equation coefficient (-)

Length $(m)$

Mass flow rate $\left(\mathrm{kgs}^{-1}\right)$

Reduced mass flow rate $\left(k g K^{1 / 2} s^{-1} b a r^{-1}\right)$

Rotational speed (rpm)

Reduced rotational speed $\left(r p m K^{-1 / 2}\right)$

Number of blades (-)

Pressure $(\mathrm{Pa})$

Perfect gas constant $\left(\mathrm{Jkg}^{-1} \mathrm{~K}^{-1}\right)$

Rotor radius $(m)$

Standard deviation $(-)$ 


$\begin{array}{ll}s p & \text { Spacing between stator blades }(m) \\ t & \text { Blades and/or channel width }(m) \\ T & \text { Temperature }(K) \\ \dot{Q} & \text { Heat flux }(W) \\ u & \text { Blade tip speed }\left(m s^{-1}\right) \\ v & \text { Absolute velocity }\left(m s^{-1}\right) \\ V G T & \text { VGT position }(\%) \\ \dot{W} & \text { Power }(W) \\ w & \text { Relative velocity }\left(m s^{-1}\right)\end{array}$

\section{Greek symbols}

$\begin{array}{ll}\alpha & \text { Absolute velocity angle }(\mathrm{rad}) \\ \beta & \text { Relative velocity angle }(\mathrm{rad}) \\ \gamma & \text { Specific heat capacities ratio }(-) \\ \delta & \text { Angle between consecutive stator blades }(\mathrm{rad}) \\ \eta & \text { Efficiency }(-) \\ \theta & \text { Tangential velocity component }\left(\mathrm{ms}^{-1}\right) \\ \Pi & \text { Pressure ratio }(-) \\ \rho & \text { Density }\left(\mathrm{kgm}^{-3}\right) \\ \sigma & \text { Blade to jet speed ratio }(-) \\ \varphi & \text { Angle of the stator vanes }(\mathrm{rad})\end{array}$

\section{Subsripts and superscripts}

$\begin{array}{ll}0 & \text { Turbine inlet station } \\ 1 & \text { Stator inlet station } \\ 2 & \text { Stator outlet station } \\ 2^{\prime} & \text { Stator throat station } \\ 2 a & \text { Stator vanes axis of rotation station } \\ 3 & \text { Rotor inlet station } \\ 4 & \text { Rotor outlet station } \\ \text { geom } & \text { Refers to geometry } \\ \text { metal } & \text { Refers to metal angle }\end{array}$




$\begin{array}{ll}N e q & \text { Refers to equivalent nozzle } \\ r e d & \text { Refers to reduced variables } \\ s & \text { Isentropic conditions and Stator } \\ t & \text { Total conditions } \\ T & \text { Refers to turbine } \\ T E & \text { Distance between stator blades axis of rota- } \\ & \text { tion and trailing edge } \\ t h & \text { Refers to throat } \\ t s & \text { Total to static } \\ - & \text { Average value }\end{array}$

\section{Introduction}

In the past years an important increment of interest in improving the prediction of transient and partial load conditions of turbocharged reciprocating internal combustion engines (ICE) has appeared. Due to the strict emission regulations engine manufactures focus engine design in operating conditions different from the traditional full load conditions. As it is showed in [1], during engine transient and partial load design conditions for the ICE the turbocharger turbine works at off-design conditions. In these off-design conditions the turbine works at high blade to jet speed ratios $(\sigma)$ or low pressure ratios and low power outputs as shown in [2] due to turbocharger wheel inertia and pulsating flow in the exhaust of the ICE. Traditional measurements of turbine maps in gas stands are unable to capture this behaviour [3]. Only a narrow range turbine map is provided by manufacturers as a standard practice. Turbine maps are necessary when using $1 \mathrm{D}$ or $0 \mathrm{D}$ modelling tools to predict the whole engine behaviour. In 1D modelling approach the one-dimensional unsteady non-homentropic mass, momentum and energy conservation laws (Euler equations) are solved. Specific source terms are used to simulate the friction and heat exchange in the pipes.

The 1D simulation codes make possible the calculation of gas dynamics engine behaviour at low computational costs. Some engine components are modelled 
with a 0D approach, using specific lumped parameter models or performance maps. That is the case of cylinders, injectors, valves, compressors and turbines which are coupled to the $1 \mathrm{D}$ computational domain as it is described in [4]. For that reason, turbocharged ICE designers must rely on map extrapolation tools when predicting engine performance outside of turbine design operative conditions [5]. It is typical in pulsating flow conditions, requiring different modelling approaches similar to the proposed in [6], where meanline one-dimensional models are discussed and in [7], where non-adiabatic pressure loss boundary condition is discussed. One-dimensional tools are also used in design process for fast evaluation of turbine capabilities as in [8]. In [9] a Taylor series expansion is used to develop a model able of predicting mass flow parameter of radial turbines.

CFD models for turbine design have been developed in [10]. This approach is useful when turbine CAD files are ready. However, this information is not always available for automotive engines simulation. Full three-dimensional simulations can reproduce turbocharger behaviour only at a very high computational cost [11] what means that these simulations are only performed at few operating points [12]. Therefore, for whole driving cycle simulations, 1D or 0D approaches must be used to keep low computational costs and an adequate precision.

In the last years, several proposals have appeared in the literature regarding this topic. Some of them are based on pure theoretical approaches [13] but use parameters in losses models that have not been proved to be general on a wide range of turbine sizes or VGT (variable geometry turbine) positions. The same can be said from [6] for adiabatic and from [7] for non-adiabatic turbines modelling. Other models are based on physical considerations but use empirical parameters for fitting stator outlet flow angles, without a clear correlation against physical values of average flow angles [14]. Furthermore, the model proposed in [14] relies on tangent functions, which are mathematically unstable during fitting procedures using numerical methods. Moreover, the model shown in [14] was only validated for blade to jet speed ratio extrapolation, not for turbocharger speed or VGT position extrapolation. Some models in the 
literature are based on the characterisation of the different losses of the turbine [15] such as passage losses or tip clearance losses [16] but no general procedure for coefficients fitting or a comprehensive model validation at highly off-design conditions have been reported yet. Other models are purely empirical and use the information of the map to fit coefficients as has been done in [17] for SI and DI engines control. A similar approach has been used in [18] for automotive engines simulation, also with a control oriented objective. A review of the advantages and disadvantages of each kind of model has been performed in [19].

As any extrapolation tool, the extrapolation models have always faced an important validation problem. The validity of the modelling can be checked for the measured conditions but not in the outside area, where it is really interesting to use the model. To overcome this problem, special tests have been designed in a gas stand to measure a turbine outside of its design range, at extremely high $\sigma$ [20]. This new approach provides wider $\sigma$ range than using a closed circuit in the compressor to extended the operational range of the turbine [21].

In the present paper, a model for turbine characteristics extrapolation is presented. The developed model is suitable to be used in $1 \mathrm{D}$ and $0 \mathrm{D}$ control oriented simulation codes. The model is capable of extrapolating to non measured VGT positions and reduced speeds. Furthermore, it has been developed based on a database of measured turbochargers and it has been validated in a high $\sigma$ range by using experimental results from special gas stand tests [20].

The main differences between the model proposed in this paper and literature models lies in the enhanced extrapolation capabilities, the generality and the low quantity of input data needed. The proposed model is able to extrapolate to non-measured VGT position maps, to non-measured reduced speeds and to non-measured blade to jet speed ratios both mass flow parameter and adiabatic efficiency. Any radial turbine can be extrapolated with the model if a standard map or a number of measured operative conditions (higher than 7) are available as an input. Therefore, the model proposed in this paper can be generally used for extrapolating different radial turbines only requiring basic geometry data.

The paper has been divided in five main sections. In section 2, a brief 
description of the experimental study is exposed. In sections 3 and 4 , the extrapolation model is exposed in detail, covering both the reduced mass flow extrapolation and the adiabatic efficiency extrapolation. Finally, in section 5, the model is also validated using the special experimental results at high $\sigma$. In section 6 , work conclusions are listed.

\section{Experimental study}

Extremely high blade to jet speed ratio experimental data were obtained in order to check the map extrapolation model. The experimental arrangement used to obtain these data is summarised in the following subsection.

\subsection{Experimental setup}

A standard turbocharger gas stand was modified so very low turbine output powers were measurable. The modifications were necessary since in normal conditions, the turbine operating point is controlled by means of the turbocharger compressor, which acts as a brake [21]. In standard turbocharger gas stands, as the rig described in [22], both the compressor inlet and outlet lines are connected to the ambient, and a back-pressure valve is placed inside the latter so the compressor flow rate can be restricted. The turbine is fed with pressurised air at its inlet, whereas its outlet is connected to the ambient. As the operating range of a radial compressor is quite limited for a given rotational speed when used in a standard gas stand, only narrow turbine maps can normally be measured. On the one hand, the maximum power consumed by the compressor, for a given speed, is produced at its maximum flow rate, which is limited due to flow choking in any zone of the inducer or diffuser inlet. On the other hand, the minimum power consumed by the compressor is limited by surge phenomena at low flow rates. The turbine produces lower power outputs when rising its $\sigma$, so the maximum value that can be measured is limited by the minimum power consumed by the compressor and the friction losses.

In the experimental campaign designed for high $\sigma$ testing, the gas stand was modified so the turbocharger compressor was used as a kind of centrifugal 
turbine. This way, the turbocharger turbine power output could be lowered and its $\sigma$ risen at constant turbo speed and in steady-state conditions, as part of the mechanical power losses could be overcome by the compressor. Pressurised air was fed to the turbocharger compressor at its inlet and expanded inside it, thus producing power instead of consuming it. A detailed description of the experimental campaign and its physical basis can be found in [20].

The turbocharger measured during this experimental campaign has a VGT. It is sized for a 2 litres turbocharged reciprocating, compression-ignition ICE. As the adiabatic efficiency of the turbine was the objective to be obtained, it was measured in almost-adiabatic conditions: the turbine and oil inlet temperatures were kept as close as possible to the compressor outlet temperature during the experiments, so the internal heat fluxes were minimised. In spite of this, residual heat transfer phenomena have an important effect on gas stand measurements as shown in [23]. When appearing, these effects have been taken into account using the correlations proposed in [24]. The ducts and the turbocharger were also thermally insulated in order to reduce the external heat transfer.

Residual heat transfer effects were anyway measured due to oil temperature increment caused by friction losses and considered to get pure adiabatic efficiency as described in [25]. The turbine flow rate, inlet and outlet pressures and inlet and outlet adiabatic temperatures were obtained experimentally, as well as the turbocharger speed, to calculate the turbine efficiency at high $\sigma$ Table 1 shows details about instrumentation errors. A summary of the results is shown in sections 4 and 5 of present paper. More details about these results can be found in [20]. The details about uncertainty calculation in experimental results and in measured turbine efficiency were already discussed in reference [26].

\subsection{Experimental outputs description}

The experiments provided the necessary data to calculate turbine map parameters: reduced speed, reduced mass flow, pressure ratio, adiabatic efficiency and $\sigma$. As it is usual in turbocharger practice several lines of constant reduced speed have been measured. 
The turbine reduced speed $n_{\text {red }}$ was computed using equation (1).

$$
n_{\text {red }}=\frac{n}{\sqrt{T_{0 t}}}
$$

Table 1: Accuracies of measurement sensors

\begin{tabular}{lll}
\hline \hline Variable & Sensor type & Accuracy \\
\hline Gas pressure & Piezoresistive & $\pm 2500 \mathrm{~Pa}$ \\
Gas and metal temperature & K-type thermocouple & $\pm 2.2 \mathrm{~K}$ \\
Gas mass flow & V-cone & $\pm 0.5 \%$ \\
Oil pressure & Piezoresistive & $\pm 2500 \mathrm{~Pa}$ \\
Oil temperature & RTD & $\pm 0.15 \mathrm{~K}$ \\
Oil mass flow & Coriolis & $\pm 0.1 \%$ \\
\hline \hline
\end{tabular}

where $n$ is the turbocharger speed and $T_{0 t}$ is the turbine total inlet temperature, according to stations numbering shown in Figure 1a. The turbine reduced flow rate $\dot{m}_{r e d}$ was computed using equation (2).

$$
\dot{m}_{\text {red }}=\frac{\dot{m} \cdot \sqrt{T_{0 t}}}{p_{0 t}}
$$

where $\dot{m}$ is the turbine mass flow rate and $p_{0 t}$ is the turbine inlet total pressure. The turbine total to static pressure ratio $\Pi_{0,4(t s)}$ is computed using equation (3).

$$
\Pi_{0,4(t s)}=\frac{p_{0 t}}{p_{4}}
$$

where $p_{4}$ is the turbine outlet pressure. The turbine adiabatic efficiency $\eta_{t s}$ is computed as the ratio of the turbine power output $\dot{W}_{T}$ and the turbine isentropic power output $\dot{W}_{T, s}$ as shown in equation (4).

$$
\eta_{t s}=\frac{\dot{W}_{T}}{\dot{W}_{T, s}}=\frac{\dot{m}_{T} \cdot \bar{c}_{p} \cdot\left(T_{0 t}-T_{4 t}\right)-\dot{Q}_{T}}{\left(\dot{m}_{T} \cdot \bar{c}_{p} \cdot T_{0 t}-\dot{Q}_{T}\right) \cdot\left[1-\left(\frac{p_{4}}{p_{0 t}}\right)^{\frac{\gamma-1}{\gamma}}\right]}
$$


where $\bar{c}_{p}$ is the average specific heat capacity at constant pressure of air, $T_{4 t}$ is the turbine outlet total temperature, $\gamma$ is the specific heat capacities ratio of air and $\dot{Q}_{T}$ is the residual heat transfer inside the turbine in almost adiabatic conditions as seen in [23] and [25]. $\dot{Q}_{T}$ comes from the oil outlet temperature increment. Oil outlet temperature is higher than oil inlet due to friction losses. The higher oil outlet temperature generates residual heat fluxes travelling from oil bearings housing to turbine housing; as oil inlet has been kept equal to turbine inlet in almost adiabatic tests. Therefore, these have to be subtracted to get adiabatic turbine power from temperature difference measurement through the turbine [25]. Finally, the blade to jet speed ratio, $\sigma$, is calculated using equation (5).

$$
\sigma=\frac{2 \cdot \pi \cdot n \cdot r_{3}}{\sqrt{2 \cdot \bar{c}_{p} \cdot T_{0 t} \cdot\left[1-\left(\frac{p_{4}}{p_{0 t}}\right)^{\frac{\gamma-1}{\gamma}}\right]}}
$$

where $r_{3}$ is the maximum turbine wheel radius Figure 1a. The experimental data will be used to validate the extrapolation model in sections 4 and 5 of the paper.

\section{Reduced mass flow extrapolation procedure}

\subsection{Equivalent nozzle model development and main hypotheses}

The extrapolation procedure is based on modelling the turbine as a single equivalent nozzle. In that way, an equation of the throat area of that equivalent nozzle must be deduced and it must depend only on easy measurable geometry of the turbine and on the information available in a standard map. In Figure 1a this procedure is sketched, where it is shown that the equivalent nozzle covers from station 0 to 4 of the radial turbine. Continuity equation can be applied to stator, rotor and equivalent nozzle, as shown in equation (6). The velocity of the equivalent nozzle in that equation can be obtained comparing the enthalpy drop of the stages (stator and rotor) with the enthalpy drop of the equivalent nozzle

[14]. Figure 1b shows the ratio of pressure drop in the rotor to total pressure 
drop in the VGT. From this comparison equation (7) can be obtained, where

the velocities $v_{2^{\prime}}$ and $w_{4}$ have been introduced as function of mass flow using equation (6). For the derivation of the equation (7) it has been assumed that $p_{3}=p_{2^{\prime}}$ and that the flow is incompressible $\left(\rho_{3}=\rho_{2^{\prime}}\right)$ due to the small size of the vaneless space. Solving for the mass flow and comparing with equation (6) again it is possible to find the expression for the equivalent nozzle area shown in equation (8) [14]. At that point it is necessary to transform this equation into an equation where only the variables available in turbine maps appear, as well as some global geometrical definitions.

$$
\begin{gathered}
\dot{m}_{T}=A_{2^{\prime}} \rho_{2^{\prime}} v_{2^{\prime}}=A_{4} \rho_{4} w_{4}=A_{N e q} \rho_{4} v_{N e q} \\
v_{N e q}^{2}=\left(\frac{\dot{m}_{T}}{A_{2^{\prime}} \rho_{2^{\prime}}}\right)^{2}+u_{3}^{2}-u_{4}^{2}+\left(\frac{\dot{m}_{T}}{A_{4} \rho_{4}}\right)^{2}-w_{3}^{2} \\
A_{N e q}=A_{4} \sqrt{\frac{1+\left(\frac{u_{4}}{v_{N e q}}\right)^{2}-\left(\frac{u_{3}}{v_{N e q}}\right)^{2}+\left(\frac{w_{3}}{v_{N e q}}\right)^{2}}{\left(\frac{A_{4}}{A_{2^{\prime}}}\right)^{2}\left(\frac{\rho_{4}}{\rho_{2^{\prime}}}\right)^{2}+1}}
\end{gathered}
$$

(a)
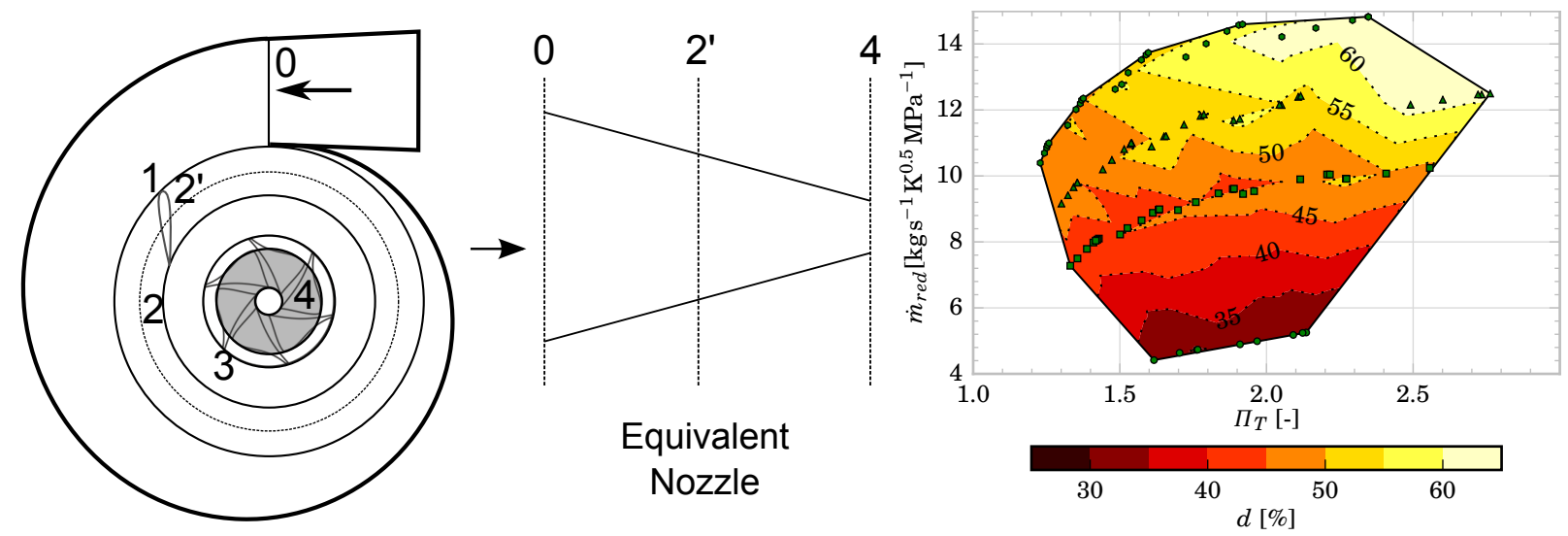

Figure 1: (a) Reduction of a radial turbine to an equivalent nozzle and stations distribution. (b) Measured ratio of pressure drop in the rotor to total pressure drop in the turbine ('d') in the VGT map [27] of T\#1A 
The model must have the capability to compute the geometrical throat section of the stator vanes $\left(A_{2^{\prime}}^{\text {geom }}\right)$ based on VGT position and geometry of the turbine. Equation (9) shows how the throat length of the stator $\left(l_{t h 2^{\prime}}\right)$ can be obtained, making use of Figure 2a and of equation (10). In order to get the necessary $\varphi_{2}^{\text {metal }}$ value for equation (9) several VGTs, corresponding to Table 2 have been characterised. Figure $1 \mathrm{~b}$ shows the mass flow map of $\mathrm{T} \# 1 \mathrm{~A}$ detailing 4 VGT positions. If detailed vanes geometry were available a more precise geometrical characterisation would be possible, as the one described in [28].Figure $2 \mathrm{~b}$ shows empirically obtained relations between stator blades average angle $\left(\varphi_{2}^{\text {metal }}\right)$ and VGT position for the three tested turbines. In the case that this information was not possible to be obtained, the average values of slope and y-intercept of the mean line shown in Figure 2b can be used. The angle of the stator vanes can then be calculated using equation (11), obtained from Figure $2 \mathrm{~b}$ for any VGT position percentage. It must be taken into account that the relations shown in Figure 2b come from cold conditions and variations at hot operational conditions, due to metal thermal expansion and loading in the blades mechanism, must be expected. These thermal expansions introduce further uncertainty in calculating geometrical throat length $\left(l_{t h 2^{\prime}}\right)$.

$$
\begin{gathered}
l_{t h 2^{\prime}}=2 r_{2} \cdot \sin (\delta / 2) \cdot \cos \left(\varphi_{2}^{\text {metal }}\right) \\
r_{2}=\sqrt{\left(r_{2 a}-L_{T E} \cdot \cos \left(\varphi_{2}^{\text {metal }}\right)\right)^{2}+\left(\sin \left(\varphi_{2}^{\text {metal }}\right) \cdot L_{T E}\right)^{2}} \\
\varphi_{2}^{\text {metal }}(\mathrm{deg})=-0.004 \cdot V G T+79.36
\end{gathered}
$$

Finally $A_{2^{\prime}}^{\text {geom }}$ can be calculated as shown in equation (12)

$$
A_{2^{\prime}}^{g e o m}=l_{t h 2^{\prime}} \cdot t_{2} \cdot n_{2}
$$


Table 2: Tested VGTs data

\begin{tabular}{llll}
\hline & T\#1A & T\#1B & T\#2 \\
\hline $\begin{array}{l}\text { Turbine wheel di- } \\
\text { ameter }[\mathrm{mm}]\end{array}$ & 40 & 39 & 38 \\
$\begin{array}{l}\text { Compressor wheel } \\
\text { diameter [mm] }\end{array}$ & & & \\
Water-cooling & yes & yes & no \\
Engine displace- & 2.0 & 2.0 & 1.6 \\
ment [1] & & & \\
\hline
\end{tabular}

(a)

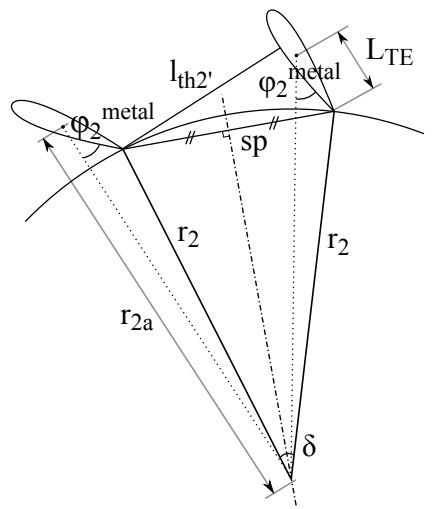

(b)

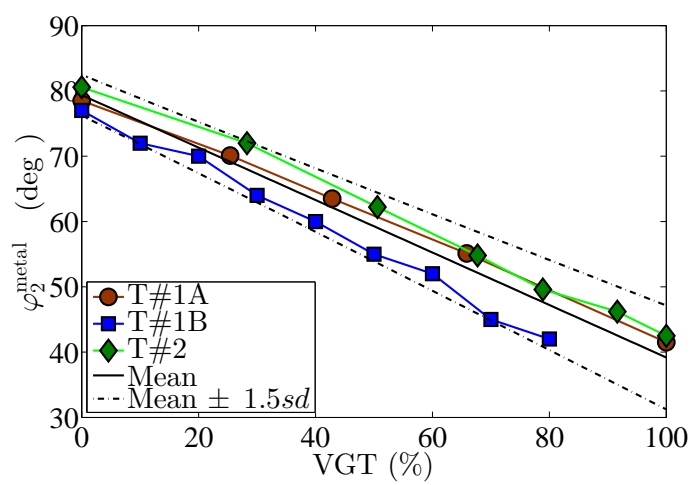

Figure 2: (a) Geometrical relations of a VGT stator vanes (b) Linear relations between stator vanes angle and VGT opening

Continuing with the simplifications of equation (8) and knowing the diameters of turbine rotor it is possible to group the terms of $u_{3}$ and $u_{4}$. After that, using the total to static turbine adiabatic efficiency definition (equation (9)) it is possible to introduce the isentropic velocity $c_{s s}$ to replace the equivalent nozzle velocity $\left(v_{N e q}\right)$. An additional approximation can be made in this point following the dimensional analysis of equation (13).

$$
\frac{v_{N e q}^{2}}{c_{s s}^{2}}=\eta_{t s}+\frac{v_{4}^{2}}{c_{s s}^{2}}=O\left[10^{-1}\right]+O\left[10^{-4}\right] \Rightarrow \frac{v_{N e q}^{2}}{c_{s s}^{2}} \approx \eta_{t s}
$$

With this approximation it is now possible to introduce the blade to jet 
speed ratio, defined in equation (5), in the equivalent nozzle area expression. At this point the equivalent nozzle area can be approximated by equation (14), where the term $\left(w_{3} / c_{s s}\right)^{2}$ is lumped in 'b' fitting coefficient.

$$
A_{N e q}=A_{4} \sqrt{\frac{1+\frac{\sigma^{2}}{\eta_{t s}}\left[\left(\frac{D_{4}}{D_{3}}\right)^{2}-1\right]+\frac{b}{\eta_{t s}}}{\left(\frac{A_{4}}{A_{2^{\prime}}}\right)^{2}\left(\frac{\rho_{4}}{\rho_{2^{\prime}}}\right)^{2}+1}}
$$

There is an inherent problem with equation (14). At certain conditions; mainly at high reduced speeds and low pressure ratios; the term inside of the square root may become negative, specially at very low values of $\eta_{t s}$. To avoid possible instabilities during extrapolations a constant average value of efficiency is assumed $\left(\eta_{t s}=\bar{\eta}_{t s}=0.8\right)$, relying on 'b' coefficient to provide sufficient numerical flexibility to the model.

Finally, it is necessary to find an expression for the density ratio shown in equation (14). Authors have stated that the hypotheses taken in [14] are not consistent enough for non-measured VGT positions extrapolation. So, they have been revised and changed here with the objective of finding an expression for the density ratio by using the equation of ideal gases and expressing the density ratio as a product of pressure ratio $\left(p_{4} / p_{3}\right)$ and temperature ratio $\left(T_{3} / T_{4}\right)$. The temperature ratio can be estimated using adiabatic efficiency of the rotor. However, rotor adiabatic efficiency is not available in turbine maps so an additional assumption is made in this point and for this single purpose: i.e. the efficiency of the rotor is equal to turbine total to static efficiency. This strong hypothesis is made for the single purpose of getting a temperature ratio and it implies the following thermodynamic assumptions:

- The polytropic index is equal in the rotor and in the stator.

- Absolute kinetic term at turbine inlet and relative kinetic term at rotor inlet are neglected.

- Turbine inlet velocity is equal to the outlet velocity $\left(v_{1}=v_{4}\right)$. 
Taking into account the previous assumption it is possible to express the area of the equivalent nozzle using equation (15).

$$
A_{\text {Neq }}=\frac{a \cdot A_{4}^{\text {geom }} \cdot \sqrt{1+\frac{\sigma^{2} \cdot\left[\left(\frac{D_{4}}{D_{3}}\right)^{2}-1\right]+b}{\bar{\eta}_{t s}}}}{\sqrt{1+\left(c \cdot \frac{A_{4}^{g e o m}}{A_{2^{\prime}}^{g e o m}}\right)^{2} \cdot \frac{\left(\frac{1}{\Pi_{2^{\prime}, 4}}\right)^{2}}{\left(1-\eta_{t s} \cdot\left(1-\left(\frac{1}{\Pi_{2^{\prime}, 4}}\right)^{\frac{\gamma-1}{\gamma}}\right)\right)^{2}}}}
$$

In this equation a new constant ('d') has been introduced (equation (16)) through the term $\Pi_{2^{\prime}, 4}$ (equation (17)). $\Pi_{2^{\prime}, 4}$ represents pressure ratio in the VGT rotor and 'd' term has been shown in Figure 1b on the VGT map of T\#1A. This means another last assumption: the stator pressure drop to total pressure drop ratio is constant for a VGT position. It is easy to obtain equation (17) from that assumption introducing the 'd' fitting coefficient.

$$
\begin{gathered}
d=\frac{p_{2^{\prime}}-p_{4}}{p_{0 t}-p_{4}} \\
\Pi_{2^{\prime}, 4}=1+d\left[\Pi_{0,4}^{t s}-1\right]
\end{gathered}
$$

\subsection{Model coefficients analysis and calibration}

Summarizing, both coefficients 'b' and 'd' of equation (15) have physical meaning, as they come from theoretical considerations, even with simplifying hypotheses. The validity of introduced hypotheses for mass flow parameter extrapolation in radial VGTs will be further checked in sections 3.3 and 5 describing experimental validation of the model. Therefore their values must have a coherent order of magnitude. The analysis of all coefficients in equation (15) is detailed below:

- Coefficient 'a': it represents the discharge coefficient of the rotor (equation (18)). As the rotor outlet geometrical area $\left(A_{4}^{\text {geom }}\right)$ is independent of VGT position 'a' can be considered constant for a given turbocharger. The 
order of magnitude of this coefficient must be between 0 and 1 based on the definition of discharge coefficient.

$$
A_{4}=A_{4}^{g e o m} \cdot a
$$

- Coefficient 'b': it comes from velocity triangles [14]. It is a difficult parameter to be calculated experimentally but its order of magnitude can be estimated as shown in equation (19). It can also be expected that more open VGT positions must give higher 'b' values than closer VGT positions; due to the higher radial velocities at rotor inlet, for the same pressure ratio and peripheral speed values.

$$
\begin{aligned}
b & =\left(\frac{v_{0}}{c_{s s}}\right)^{2}+\left(\frac{w_{3}}{c_{s s}}\right)^{2}=\frac{A_{N e q}}{A_{0}} \cdot\left(\frac{1}{\Pi_{T}}\right)^{(1 / \gamma)}+O\left[10^{-1}\right]= \\
& =O\left[10^{-1}\right]+O\left[10^{-1}\right] \rightarrow O\left[10^{-1}\right] \leq b \leq O\left[10^{0}\right]
\end{aligned}
$$

- Coefficient 'c': it represents the quotient between rotor discharge coefficient (coefficient 'a') and the stator discharge coefficient $\left(C_{D s}\right.$ as shown in equation (20)), which in case of VGT should be dependant on stator vanes position (equation (9)). For more open VGT positions $A_{2^{\prime}}^{\text {geom }}$ is high so ' $c$ ' is expected to be low. In addition 'c' must fulfil always inequation (21) since in spite of the effect of throat variation in the stator, effective section, introduced through the discharge coefficient $\left(C_{D s}\right)$, must be always below 1

$$
\begin{gathered}
A_{2^{\prime}}=A_{2^{\prime}}^{g e o m} \cdot C_{D s} \\
C_{D s}=\frac{a}{c} \leq 1
\end{gathered}
$$

- Coefficient 'd' (equation (16)): from experimental measurements of pressure in the space between stator and rotor in a VGT, it is possible to estimate the order of magnitude of the coefficient ' $d$ ' [27] and to confirm 
that the assumption of constant value for a given VGT position is coherent for small radial VGTs. Figure $1 \mathrm{~b}$ shows that the coefficient increases with VGT opening with a variation in the range of $[0.35,0.6]$.

Once the equivalent nozzle area (equation (15)) is known, the reduced mass flow can be calculated using the expression of flow through an orifice with isentropic expansion, equation (22).

$$
\dot{m}_{r e d}=A_{N e q} \sqrt{\frac{\gamma}{R}}\left(\frac{1}{\Pi_{0,4}^{(t s)}}\right)^{\frac{1}{\gamma}} \sqrt{\frac{2}{\gamma-1}\left[1-\left(\frac{1}{\Pi_{0,4}^{(t s)}}\right)^{\frac{\gamma-1}{\gamma}}\right]}
$$

As it has been already explained, the extrapolation model discussed above is evolved from a previous model described in [14]. That model had the problem of being unable to extrapolate to non-measured VGT positions. Their hypotheses have been revised and improved here. Nevertheless, in order to get the new extrapolation capabilities the following procedure is also needed.

The main approach to develop the possibility of extrapolation to VGT positions is based on the analysis of the physical meaning of the fitting coefficients of the model. These coefficients are constant for a given VGT position, i.e. they are independent of turbine speed and of pressure ratio.

Table 3: Coefficient 'a' values

\begin{tabular}{lllll}
\hline & Average & T\#1A & T\#1B & T\#2 \\
\hline$a \pm s d$ & $0.40 \pm 0.07$ & 0.41 & 0.47 & 0.33 \\
\hline
\end{tabular}

Using the turbochargers listed in Table 2, it is possible to provide a first approach for the behaviour of the fitting coefficients that give good precision in terms of reduced mass flow prediction compared to experiments. So fitting the coefficients of equation (15) for several VGTs it is possible to survey their behaviour with VGT position. The fitting is performed using the available data of the map in which the reduced mass flow is known. Previously described physical trends have been imposed in the fitting procedure, for instance the 'b' 
coefficient of more open VGT position is imposed to be higher or equal than for the closer position. Significance test have been performed to check the necessity of the different coefficient proving each of them to be statistically significant with a p-value lower than 0.05 .

In Figure 3 the obtained results for the fitting coefficients that vary with VGT position ('b', 'c' and 'd') are shown for the turbochargers listed in Table 2. This results were used to detect the trends in the coefficients. For the coefficient 'b' an increasing trend is obtained, according to the expected behaviour. Figure 3a shows that the values of this coefficient are close to a linear behaviour of positive slope. For 'c' coefficient the trend with VGT position must be decreasing; this has been confirmed in Figure 3c, obtained from the fitting of several VGTs and several positions after imposing such a negative trend. Again 'c' trend is close to linear behaviour but now with a negative slope. Coefficient 'd' behaviour is in accordance with experimental results from Figure 1b and shows similar positive trend than constant 'b', as it is shown in Figure 3e. In that way, coefficients dependence on VGT position has been obtained.

\subsection{Model validation}

Using the previous information it is possible to provide an imposed trend for the global map fitting. Only one fitting will be now needed for each turbocharger in which 'a' will be constant and a linear trend with VGT position for the other three coefficients will be imposed. In that way, seven coefficients must be fitted using a non-linear fitting procedure for each VGT. The values of the discharge coefficient of the rotor ('a'), for the three turbochargers, are summarised in Table 3. It can be observed that for $\mathrm{T} \# 2$ rotor discharge coefficient ('a') is lower than for $\mathrm{T} \# 1 \mathrm{~A}$ and $\mathrm{T} \# 1 \mathrm{~B}$, probably due to lower wheel diameter. As initial values for the fitting, average values from the dependence study have been used and the upper and lower bounds are 3 times standard deviation. Furthermore it is necessary to add the condition of equation (21) to make 'c' coefficient to be fully physical, as the discharge coefficient of the stator cannot be higher than unity. In that way the results of Figure 3b, Figure 3d and Figure 3f have been 
obtained for the three coefficients and the three VGTs. The linear fitting of the 'b', 'c' and 'd' constants is shown for the three VGTs as well as the average value and the boundaries for the fitting of new turbochargers. Lower boundary of 'b' coefficient is zero instead of using standard deviation in order to avoid negative values, which are not physically possible. Lower boundary of 'c' is calculated to avoid stator discharge coefficient values higher than one (equation (21)).

(a)

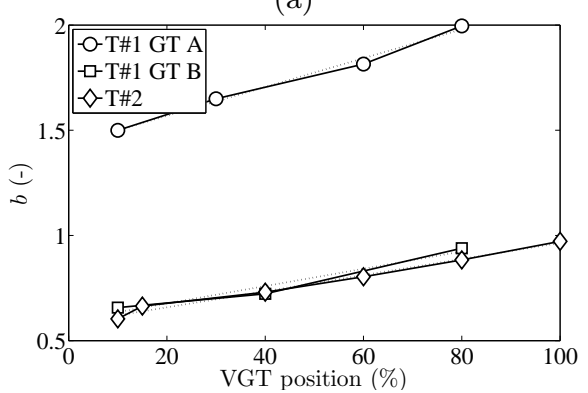

(c)

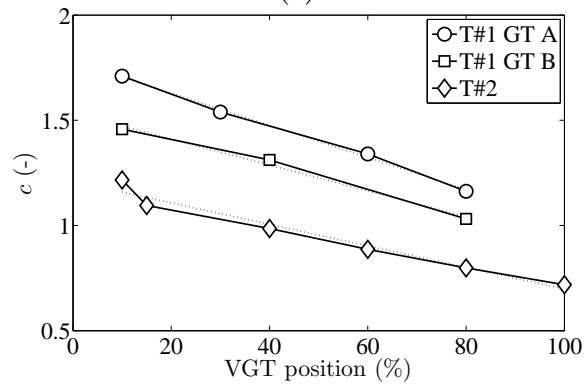

(e)

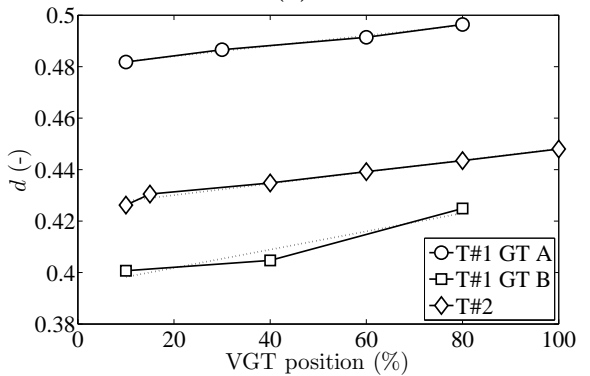

(b)

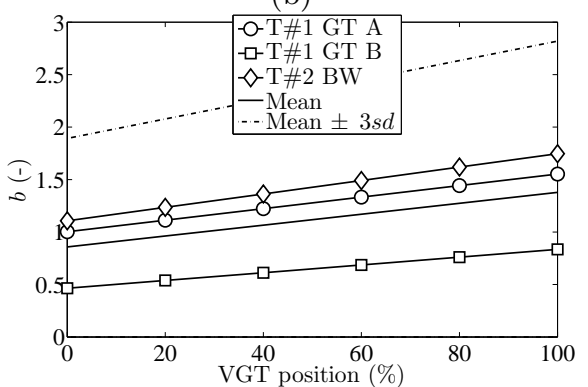

(d)

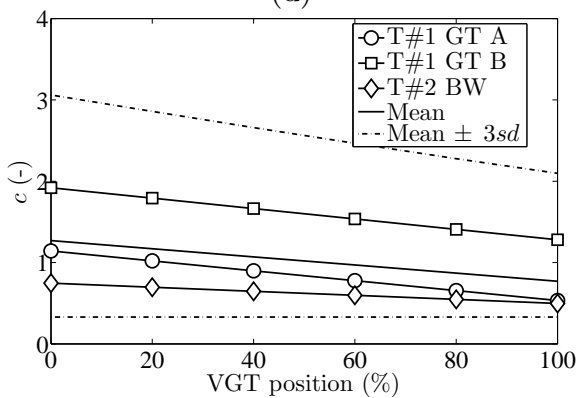

(f)

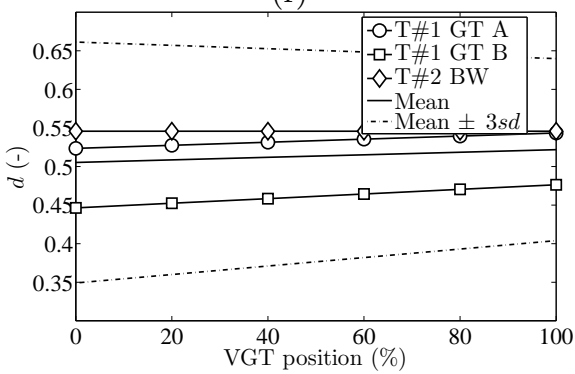

Figure 3: Reduced mass flow coefficients dependence with VGT position (a, c and e) and final fitted coefficients ( $b, d$ and $f$ )

In that way, for extrapolating a new turbine reduced mass flow map using 
(a) $\mathrm{T} \# 1 \mathrm{~B}$

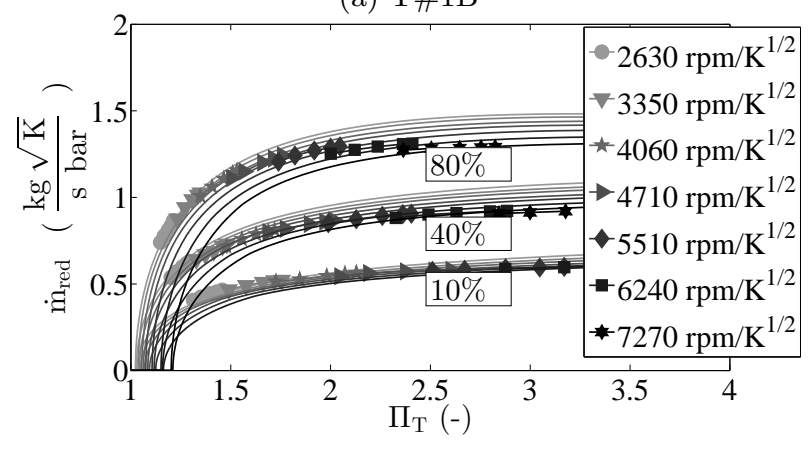

(b) $\mathrm{T} \# 2$

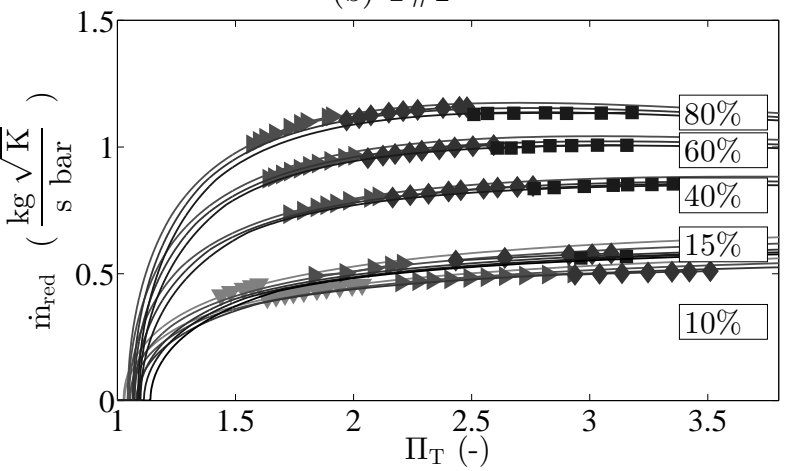

(c) $\mathrm{T} \# 1 \mathrm{~B}$ and $\mathrm{T} \# 2$

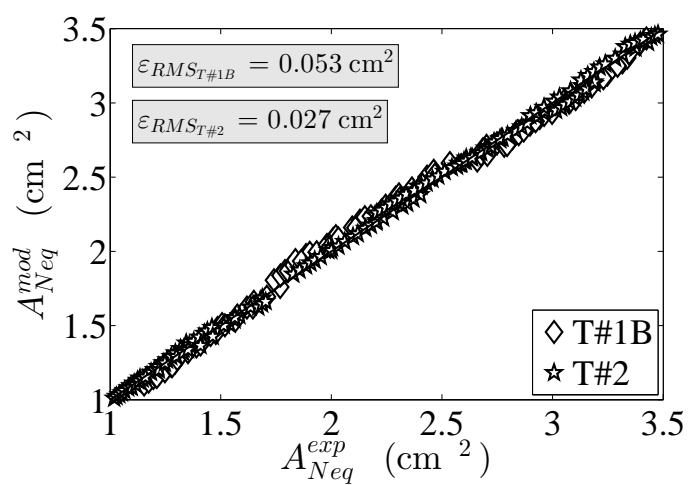

Figure 4: Fitted equivalent area and reduced mass flow for T\#1B (a) and for T\#2 (b) and measured versus modelled $A_{N e q}(\mathrm{c})$

this approach a first fitting of seven coefficients must be done using the data from the map. After that fitting the reduced mass flow for any VGT position and pressure ratio or reduced speed can be calculated.

The values of the fitted coefficients correspond to the mass flow parameter fittings shown in Figure 4 where dots correspond to measured reduced mass flow and lines to interpolated and extrapolated values for different VGT positions of $\mathrm{T} \# 1 \mathrm{~B}$ and $\mathrm{T} \# 2$. Figure 4 shows that the errors in modelling reduced mass flow are small enough to consider valid the above explained procedure. Figure 4 also shows the calculated values of $A_{N e q}$ that range bewteen $1 / 3$ and $1 / 10$ of $A_{0}^{\text {geom }}$ (refers to station 0 in Figure 1a), depending on VGT position, mass flow and turbo speed. In case of T\#2, Figure $4 \mathrm{~b}$, the values of the most open VGT 
position (80\%) have not been used for model fitting but extrapolated.

\section{Adiabatic efficiency extrapolation model}

\subsection{Model development and main hypotheses}

In order to improve efficiency fitting model it is necessary to extrapolate both in rotational speeds and in VGT position. As the model constants developed in [14] are dependant on both variables new revision and analysis must be performed. The procedure to develop the model is based on the analysis of the available data of the turbines used to refine the models.

As described in [14] the efficiency extrapolation is based on using the Euler equation of turbomachinery and assuming constant meridional component velocities. In that way in equation (23), which represents the definition of total to static adiabatic efficiency, it is possible to express the numerator in terms of velocities using Euler equation and turbine enthalpy drop as shown equation (24). The tangential velocities in that equation can be expressed in terms of meridional velocity using equation (25) and equation (26). Using them now in equation (23) and taking into account the isentropic evolution in the denominator it is possible to obtain equation (27). From these assumptions it is possible to obtain equation (28) for constant tip speed maps using the definition of $\sigma$. It is worth noting the dependence of equation (28) on $A_{N e q}$ term that must be calculated using equation (15). From equation (28) the tangent of rotor inlet angle $\left(\alpha_{3}\right)$ is a numerically unstable term. However, a transformation can be used to convert rotor inlet angle into stator outlet angle as shown in equation (29), using mass flow and angular momentum conservation equations [1]. Coefficient $z_{3}^{\text {geom }}$ is a geometrical coefficient that can be obtained theoretically from Figure $2 \mathrm{a}$, as shown in equation (30), where $l_{t h 2^{\prime}}$ can be obtained from equation (9) and $\varphi_{2}^{\text {metal }}$ for equation (11) respectively and 'c' coefficient is defined in equation (21). In that way the dependence with VGT position has been also introduced here. The coefficient 'c' has been fitted previously along with the rest of the reduced mass flow coefficient using the available data of the map. From all the 
previous steps, equation (31) can be written for the extrapolation, where some terms have been lumped into $K_{i}$ coefficients for simplification (equations (32), (33) and (34)). In equation (31), $K_{2}^{*}$ coefficient, shown in equation (34), plays an important role as a fitting constant (' $z$ ') has been added multiplying the sine function. The rest of the parts of efficiency equation (31) are related to physical values from turbine geometry or from the map as it has been already described in [14]. $\varphi_{2}^{\text {metal }}$ and $\beta_{4}^{\text {metal }}$ assumes that there are negligible deviation angles in expansion stages, what is usually accepted at high pressure ratios [1].

$$
\begin{aligned}
& \eta_{t s}=\frac{T_{0 t}-T_{4 t}}{T_{0 t}-T_{4 t s}} \\
& \dot{W}=\dot{m} c_{p}\left(T_{0 t}-T_{4 t}\right)=\dot{m}\left(u_{3} v_{\theta 3}-u_{4} v_{\theta 4}\right) \\
& v_{\theta 3}=v_{0} \tan \alpha_{3} \\
& v_{\theta 4}=u_{3}\left(\frac{r_{4}}{r_{3}}\right)-v_{0} \tan \beta_{4} \\
& \eta_{t s}=\frac{u_{3} v_{0} \tan \alpha_{3}-\left[u_{3}\left(\frac{r_{4}}{r_{3}}\right)-v_{0} \tan \beta_{4}\right] u_{3}\left(\frac{r_{4}}{r_{3}}\right)}{c_{p} T_{0 t}\left(1-\left(\frac{1}{\Pi_{0,4}^{(t s)}}\right)^{\frac{\gamma-1}{\gamma}}\right)} \\
& \eta_{t s}= \\
& =-2\left(\frac{r_{4}}{r_{3}}\right)^{2} \sigma^{2}+2 \frac{A_{N e q}}{A_{0}^{g e o m}}\left(\tan \alpha_{3}+\frac{r_{4}}{r_{3}} \tan \beta_{4}\right)\left[\frac{1}{\Pi_{0,4}^{(t s)}}\right]^{\frac{1}{\gamma}} \sigma \\
& \tan \alpha_{3}=z_{3}^{g e o m} \sin \varphi_{2}^{\text {metal }} \\
& z_{3}^{\text {geom }}=c \cdot \frac{r_{2} \cdot 2 \pi \cdot t_{3}}{t_{2} \cdot l_{t h 2^{\prime}} \cdot n_{b}} \cdot \frac{A_{0}^{\text {geom }}}{A_{3}^{\text {geom }}}
\end{aligned}
$$


(a)

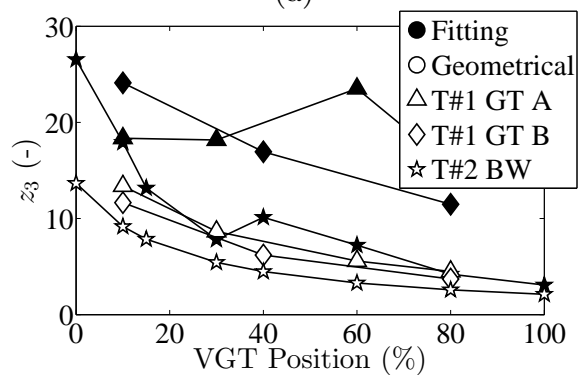

(b)

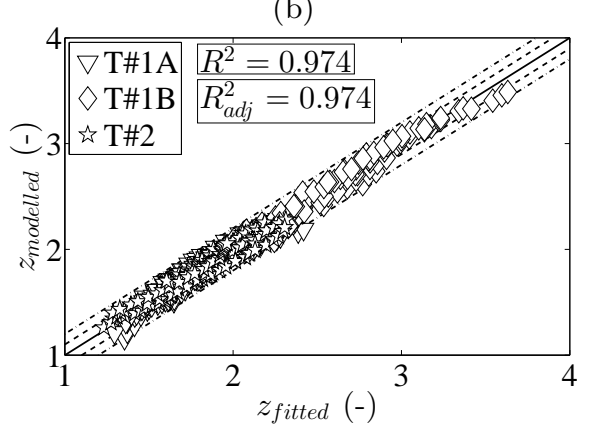

Figure 5: Difference between fitted and geometrical $z_{3}^{g e o m}$ coefficient (a) and modelled 'z' versus fitted 'z' (b)

$$
\begin{gathered}
\eta_{t s}=-K_{1} \sigma^{2}+K_{2}^{*}\left(1-\frac{K_{3}}{\sigma^{2}}\right)^{\frac{1}{\gamma-1}} \cdot \sigma \\
K_{1}=2\left(\frac{r_{4}}{r_{3}}\right)^{2} \\
K_{3}=\frac{u_{3}^{2}}{2 c_{p}} \\
K_{2}^{*}=\quad 2 \frac{A_{\text {Neq }}}{A_{0}^{\text {geom }}}\left(z \cdot z_{3}^{\text {geom }} \sin \left(\varphi_{2}^{\text {metal }}\right)+\sqrt{\frac{K_{1}}{2}} \tan \left(\beta_{4}^{\text {metal }}\right)\right)
\end{gathered}
$$

The reason for using a fitting coefficient ' $z$ ' lies in the various simplifications made to obtain equation (31) that make impossible a good fitting of the efficiency, specially if off-design conditions must be covered. For example, assuming radial velocity equal to the axial one, assuming incompressible flow between stator and rotor stages and negligible flow deviation in stator and rotor blades Indeed, comparing the $z_{3}^{\text {geom }}$ coefficient using equation (30) and fitting it to match experimentally obtained adiabatic efficiency gives different results as shown in Figure 5a. 


\subsection{Model calibration and validation}

There is a fitting ' $z$ ' coefficient for each point of turbine map. If this coefficient is calculated and plotted against blade to speed ratio and reduced speed, different planar surfaces appear one for each VGT position. From these surfaces the most simple approach is to use linear decreasing trend for blade to speed ratio, being the slope and the $\mathrm{y}$-intercept values linearly dependant on reduced speed. As the normal vector of the surfaces is similar the VGT dependence can be added directly in the independent term of the surface equation. This is done considering that the ' $z$ ' coefficient tends to increase until the maximum efficiency VGT position is reached and decrease later on. Therefore a parabolic trend with VGT position is proposed since maximum efficiency is reached around $60 \%$ of VGT opening. All these considerations lead to equation (35) for the ' $z$ ' coefficient where $n_{r e d}$ is in $\left(r p m / K^{1 / 2}\right)$ and VGT is in (\%). In this equation, six constants must be fitted for a given turbocharger using the data of the whole map (all available positions). In Figure 5b the level of correlation between fitted ' $z$ ' values and modelled 'z' values using equation (35) is shown. It can be observed that modelled values correlate with the fitted ones as proved by the $R^{2}$ and $R_{a d j}^{2}$ values. Significance test have been performed to check the necessity of the different coefficient proving each of them to be statistically significant with a p-value lower than 0.05. The standard deviation of the six coefficients are shown in the third column of Table 4. It is advised to use three times the standard deviation for new calibrations boundaries.

$$
z=-\left(a^{\prime} \cdot n_{\text {red }}+b^{\prime}\right) \cdot \sigma+\left(c^{\prime} \cdot n_{\text {red }}+d^{\prime} \cdot V G T^{2}+e^{\prime} \cdot V G T+f^{\prime}\right)
$$

In Figure 6 a flowchart of the procedure used to extrapolate mass flow and efficiency is presented. Following the flowchart, the extrapolation procedure starts with the input of the available map data. Using this information the equivalent nozzle area can be solved from equation (22) and used in a non-linear fitting procedure in order to calibrate the coefficients 'a', 'b', 'c' and 'd'. For that purpose the boundaries of the different coefficients for the fitting procedure 
are taken from Table 3 and Figures 3b, 3d, 3f. Using the fitted 'c' value and the information from the map the efficiency fitting coefficients are calibrated. After this step all the necessary coefficients are calibrated so the system of equations composed of equation (15) and equation (31) can be solved with an iterative procedure to obtain the extrapolated values of equivalent nozzle area and efficiency. Finally, the extrapolated mass flow parameter is obtained from equation (22) substituting the extrapolated equivalent nozzle area.

After fitting both the reduced mass flow coefficients and the efficiency coefficients using the data of the map, the model can be used for extrapolations. As the efficiency appears in the equivalent nozzle area (equation (15)) and the equivalent nozzle area appears in the efficiency expression (equation (31)) both equations must be solved at the same time. It can be done using an iterative procedure as defined in [29]. In Figure 7 the modelled efficiency is plotted against the measured one for the whole map of each turbocharger and the root mean square error is shown. In Figure 7 the solid red line indicates perfect fit, the dashed line indicates 2.5 efficiency points deviation and the dash and dotted line indicates 5 efficiency points deviation. In Figure 8 the model is extrapolating in blade to jet speed ratio using all the available experimental data to fit the coefficients of the model. Exception is made for the $80 \%$ VGT position in T\#2 that has been fully extrapolated (Figure 8f) while the rest of the cases were interpolated between measured points. Good agreement between experimental data (dots) and extrapolated results (lines) can be observed as deduced from Figure 7.

Figure $8 \mathrm{f}$ shows that for $4874 \mathrm{rpm} / K^{1 / 2}$ the measured efficiency is equal to the corresponding to $5814 \mathrm{rpm} / K^{1 / 2}$ what makes no sense. The model extrapolation is showing a more coherent behaviour and probably correcting measurements errors. 


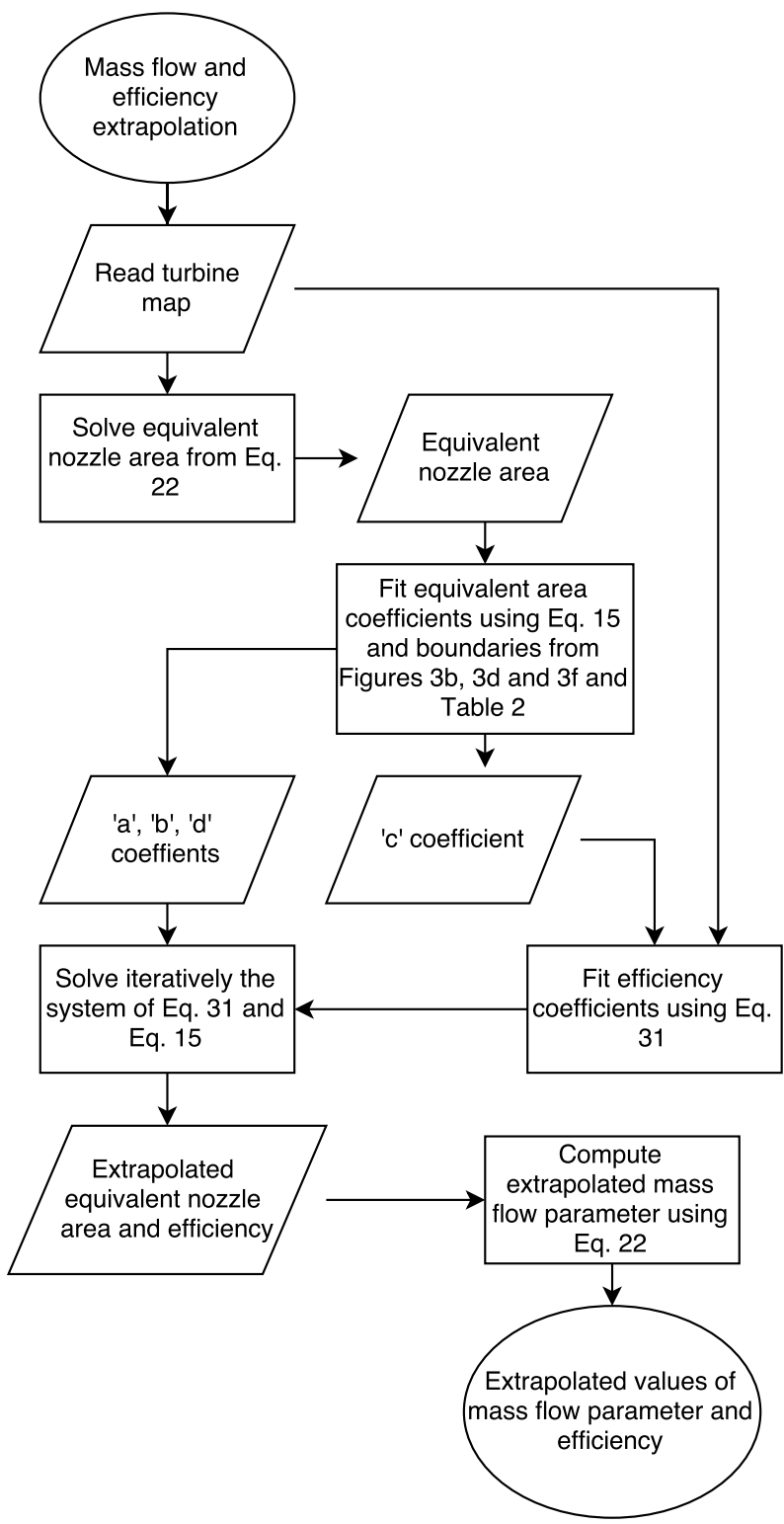

Figure 6: Procedure for mass flow parameter and efficiency extrapolation 
Table 4: Efficiency coefficients average and standard deviation

\begin{tabular}{lll}
\hline Coefficient & Average & $s d$ \\
\hline$a^{\prime}$ & $1.47 \cdot 10^{-4}$ & $3.58 \cdot 10^{-4}$ \\
$b^{\prime}$ & 3.33 & $3.34 \cdot 10^{-1}$ \\
$c^{\prime}$ & $3.59 \cdot 10^{-4}$ & $3.21 \cdot 10^{-4}$ \\
$d^{\prime}$ & $-7.67 \cdot 10^{-5}$ & $9.05 \cdot 10^{-5}$ \\
$e^{\prime}$ & $2.73 \cdot 10^{-2}$ & $9.45 \cdot 10^{-3}$ \\
$f^{\prime}$ & 1.68 & $2.38 \cdot 10^{-1}$ \\
\hline
\end{tabular}

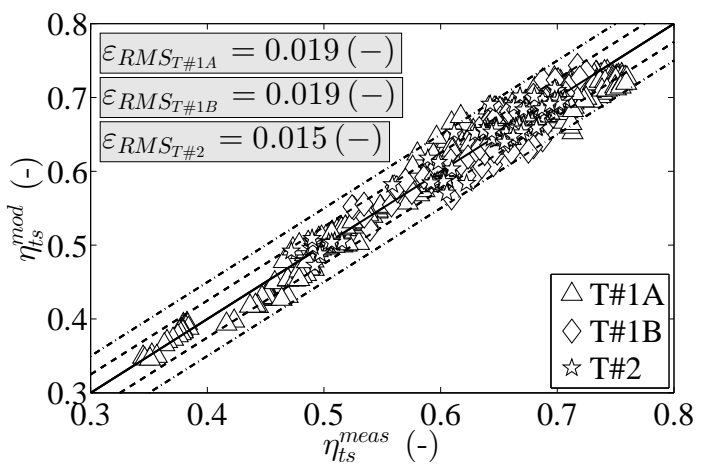

Figure 7: Root mean square error of efficiency fitting for the different turbochargers 
(a) T\#1A: VGT $10 \%$

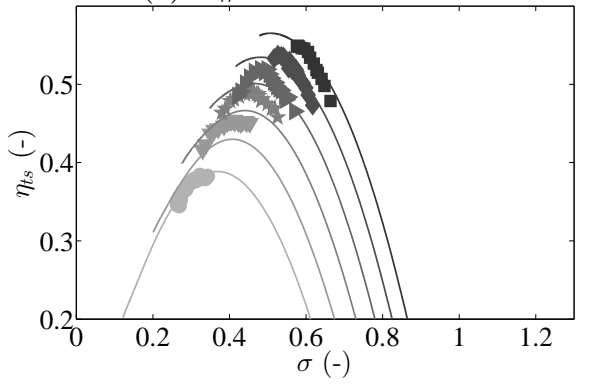

(c) T\#1B: VGT 10\%

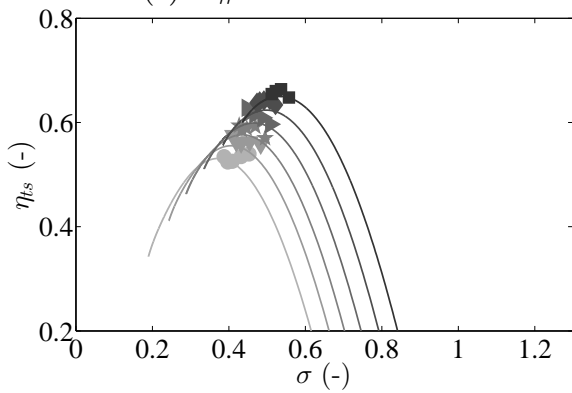

(e) T\#2: VGT 10\%

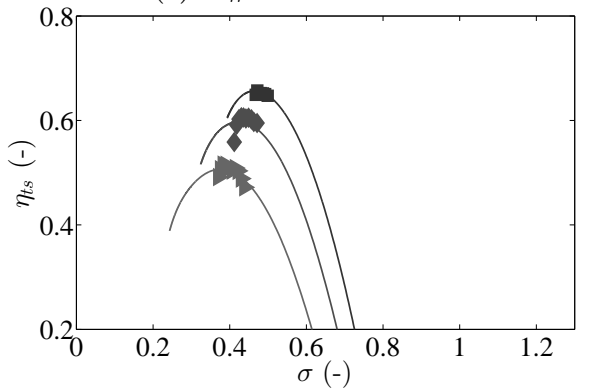

(b) T\#1A: VGT $60 \%$

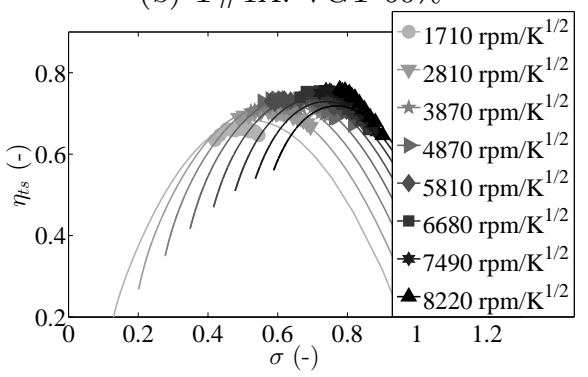

(d) T\#1B: VGT $80 \%$

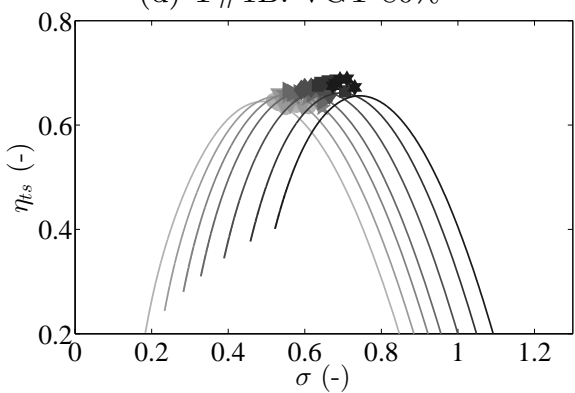

(f) T\#2: VGT $80 \%$

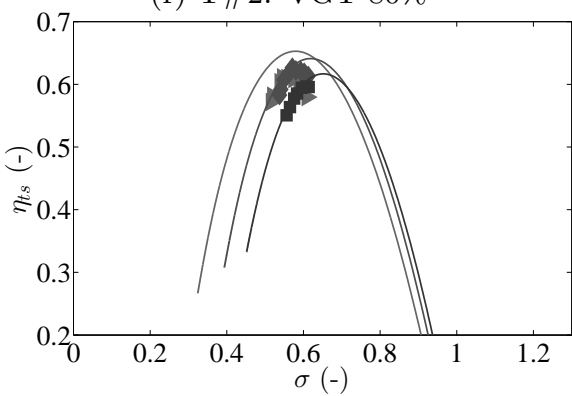

Figure 8: Efficiency extrapolation in blade to jet speed ratio for different VGT positions of $\mathrm{T} \# 1 \mathrm{~A}, \mathrm{~T} \# 1 \mathrm{~B}$ and $\mathrm{T} \# 2$ (dots correspond to experimental data and solid lines to model results)

\section{Discussion of model results at high blade to jet speed ratio extrap-} olation

Figure 9 shows the model results against the experimental data for T\#1A corresponding to the extrapolation results for reduced mass flow rate. Figure 9 shows the experimental data as points and the model results as solid lines. In

Figure 9, the model is fitted using only five points per speed line, the ones of 
maximum pressure ratio (minimum $\sigma$ ) corresponding to the full points in Figure 9. Indeed, neither the maximum nor the minimum rotational speeds for each VGT have been used during the fitting process, so Figures 9a and 9f are only extrapolated results. In this way the model has to extrapolate in both $\sigma$ and turbine reduced speed. Therefore, $1706 \mathrm{rpm} / \mathrm{K}^{1 / 2}$ and $6679 \mathrm{rpm} / \mathrm{K}^{1 / 2}$ have been fully extrapolated.

The model shows very good agreement with the experimental data when extrapolating at both lower and higher reduced speeds. At extremely low expansion ratios (high $\sigma$ ), the error starts to grow: it occurs at points where the adiabatic efficiency of the turbine is lower than zero and it consumes power instead of producing it, so very off-design flow patterns should take place in the turbine at those conditions [20]. Biggest errors are shown at VGT $80 \%$ and VGT $10 \%$ at reduced speed of $4874 \mathrm{rpm} / \sqrt{K}$ (figure $9 \mathrm{~d}$ )

Figure 10 shows the model extrapolation results for efficiency against blade to jet speed ratio. Filled point correspond to the data used for model fitting and empty points correspond to data used for blind checking. The mean square error of the whole extrapolation in this case is $\varepsilon_{R M S}=0.02(-)$. Only the experimental data corresponding to central reduced speeds and low $\sigma$ were used for model fitting (bold points in Figure 10). In Figure 10d VGT $80 \%$ position was fully extrapolated by the model (all experimental points are empty). In this case the model is able to reproduce with good precision an entire VGT position, up to very high $\sigma$. The differences between the model and the experimental data are maximum at the reduced speed of $4874 \mathrm{rpm} / \sqrt{K}$ and a VGT position of $60 \%$. This might be explained by the experimental error, caused by the very low enthalpy drops measured in the turbine at high $\sigma$ [20]. They are affected by the residual heat transfer effects since at high $\sigma$ uncertainty is introduced, even when measuring in almost adiabatic conditions and when compensating these effects. In general turbine adiabatic efficiency experimentally obtained is affected by the relatively high combined uncertainty of the turbine enthalpy drop, residual heat transfer and isentropic power at very low speeds. At other speeds, the worst results have an error of $5 \%$ to $7 \%$ points of efficiency. However, 


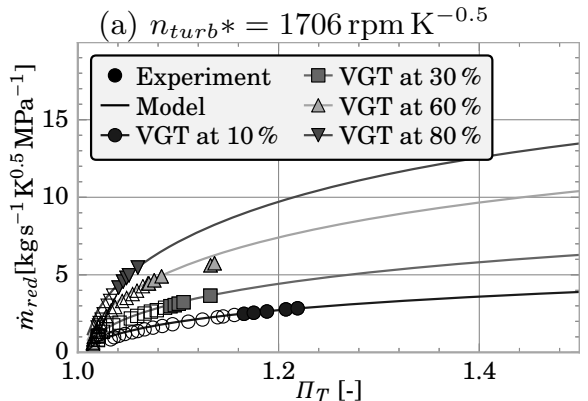

(c) $n_{\text {turb }} *=3874 \mathrm{rpm} \mathrm{K}^{-0.5}$

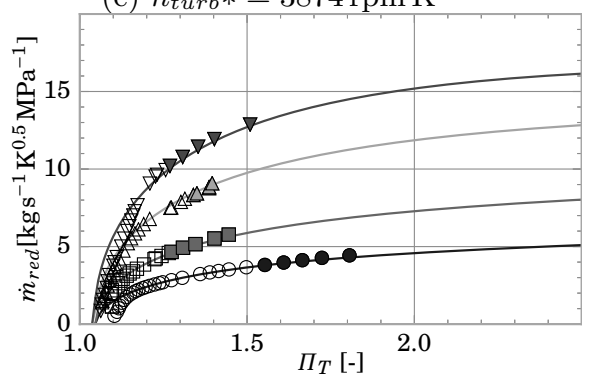

(e) $n_{\text {turb }} *=5814 \mathrm{rpm} \mathrm{K}^{-0.5}$

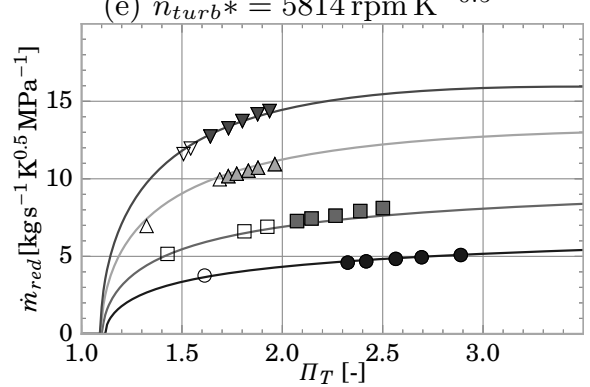

(b) $n_{\text {turb }} *=2811 \mathrm{rpm} \mathrm{K}^{-0.5}$

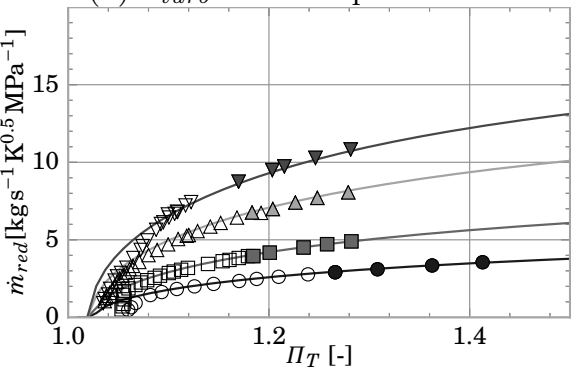

(d) $n_{\text {turb }} *=4874 \mathrm{rpm} \mathrm{K}^{-0.5}$

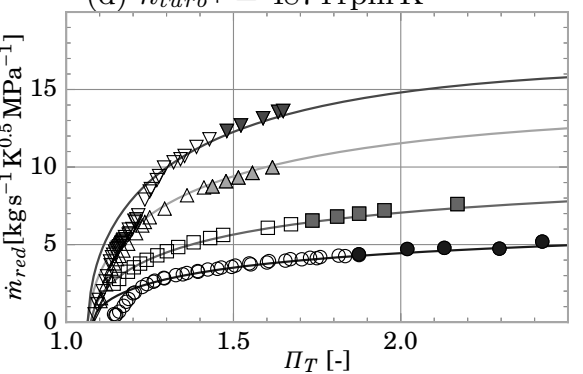

(f) $n_{\text {turb }} *=6679 \mathrm{rpm} \mathrm{K}^{-0.5}$

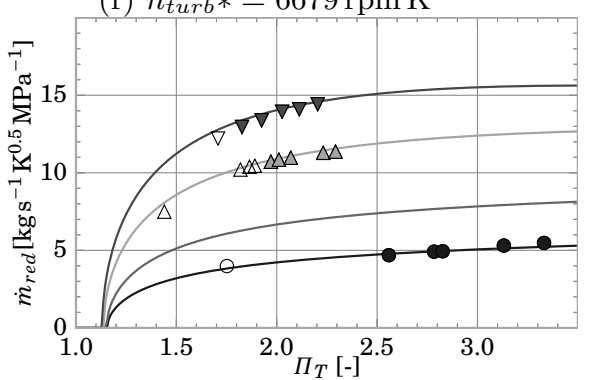

Figure 9: Reduced mass flow rate extrapolation results where extreme rotational speeds were fully extrapolated (dots correspond to experimental data and solid lines to model results)

\section{Conclusions}

In this paper, a method for extrapolating radial turbine performance in terms of VGT position, rotational speed and blade speed ratio is presented. In order to fully validate the model, a special turbocharger gas stand has been also used, which provides means for measuring at very high blade to jet speed ratio. 
(a) T\#1A: VGT $10 \%$

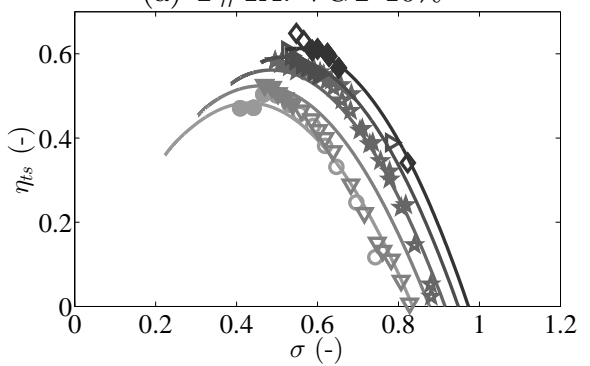

(c) T\#1A: VGT $60 \%$

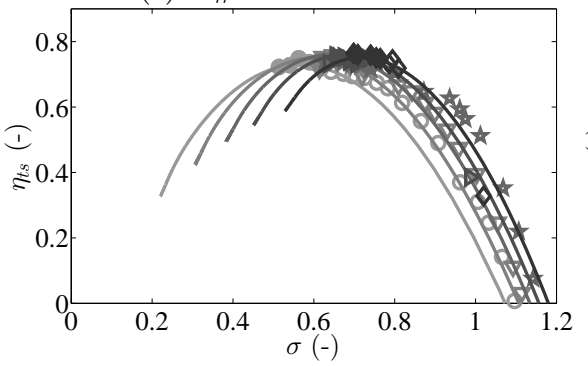

(b) T\#1A: VGT $30 \%$

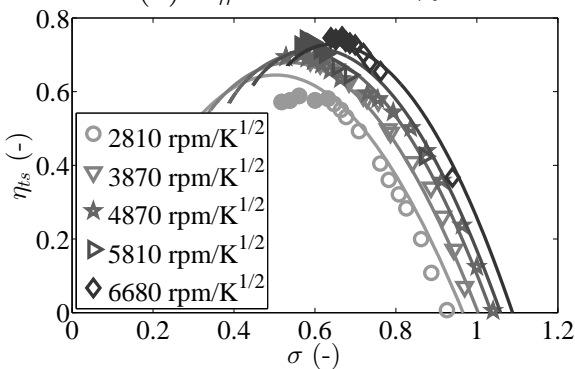

(d) T\#1A: VGT $80 \%$

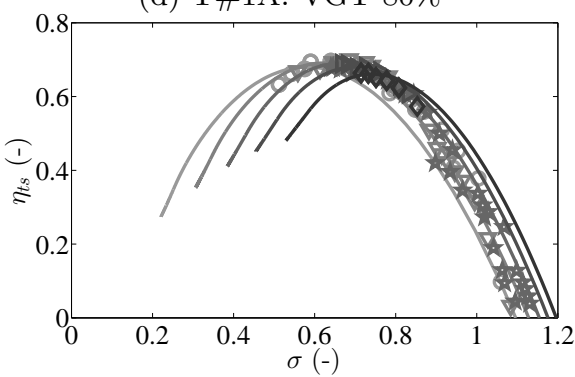

Figure 10: Efficiency extrapolation results for T\#1A checking model capabilities at high blade to jet speed ratio (dots correspond to experimental data and solid lines to model results)

The method uses thirteen calibration coefficients which are fitted using a limited set of available turbine map data. Seven coefficients are fitted independently for the reduced mass flow and six for the efficiency. The reduced mass flow calibration coefficients must be fitted in the first place since one of them, the quotient between the rotor and the stator discharge coefficients (coefficient 'c'), is used in the efficiency model equation.

The reduced mass flow and the efficiency variables are interrelated since the reduced mass flow appears in the efficiency equation and the efficiency appears in the mass flow equation. As both variables appear implicitly, after fitting the calibration coefficients, a system with the reduced mass flow and the efficiency equations must be solved, using an iterative procedure, for extrapolation purposes.

The model shows good agreement with the experimental data even when it is calibrated with a very limited set of data. Both mass flow and efficiency 
can be extrapolated beyond typical turbine map measured range in whatever variable, i.e. VGT position, reduced speed and blade to jet speed ratio.

One of the main advantages of the model is that it can be used easily for any radial VGT or FGT (fixed geometry turbine), as the geometrical parameters are easy to measure and the initial conditions and boundaries for the fitting procedure have been stated in the paper. A good extrapolation is expected for any energy conversion system using radial turbines since model self calibration coefficients do not depend on turbine size and model is based on reduced or non-dimensional parameters for representing turbines performance. It is only necessary to have a standard turbine map measured in almost adiabatic conditions (or adiabatized) and with at least two VGT positions to fit the necessary coefficients for reduced mass flow and efficiency extrapolation. Nevertheless, the higher the number of available VGT positions the better for the quality of the extrapolation model.

The accuracy of the extrapolation model regarding mass flow parameter is high in the intermediate expansion ratio range. At low expansion ratio the model is still able to reproduce the behaviour of most of the experimental points, even with negative turbine adiabatic efficiencies. The accuracy of the efficiency model is high in the intermediate $\sigma$ range. At high $\sigma$ the model curves cross most of the experimental points, mainly at intermediate turbine reduced speeds. Good results for both variables are also obtained when extrapolating turbine reduced speeds. Finally, the prediction of full VGT position maps is also accurate in the whole expansion ratio range.

The main limitation of this approach is that the model has to be calibrated for each turbine using turbocharger manufacturers map data or some operative points tested a priori to get model maximum predictability. Since there are 13 coefficients ( 7 for mass flow parameter and 6 for efficiency), at least 7 turbine operative points must be available for model self-fitting procedure. The higher the number of points the better the fitting results. If no data are available the predictions of the model will be less accurate but can still be possible by using average values of the proposed model coefficients. 
One possible future work is to use a CFD approach in a similar way to the proposed in [30] in order to double check the validity of the proposed methods. Furthermore, available experimental off-design measurements can be used for validation.

\section{Acknowledgements}

The authors of this paper wish to thank M.A. Ortiz for his invaluable help during the experimental setup and to Arnau Blasco for his hard data fitting work. This work has been partially supported by the Spanish Ministry of Economy and Competitiveness through grant No. TRA2013-40853-R.

\section{References}

[1] N. Watson, M. Janota, Turbocharging the Internal Combustion Engine, Macmillan Publishers, Ltd., 1982.

[2] H. Moustapha, M. Zelesky, N. Baines, D. Japikse, Axial and radial turbines, Concepts NREC, Vermont, 2003.

[3] H. Hiereth, K. Drexl, P. Prenninger, Charging the internal combustion engine, Springer, 2007.

[4] M. Barratta, E. Spessa, Numerical Simulation Techniques for the Prediction of Fluid-Dynamics, Combustion and Performance in IC Engines Fuelled by CNG, Computational Simulations and Applications, InTech, Dr.Zhu Jianping (Ed.), 2011. doi:10.5772/25081.

[5] G. Martin, P. H. C. Caillol, V. Talon, Implementing turbomachinery physics into data map-based turbocharger models, SAE technical paper 2009-01-0310.

[6] M. Chiong, S. Rajoo, A. Romagnoli, A. Costall, R. MartinezBotas, Integration of meanline and one-dimensional methods 
for prediction of pulsating performance of a turbocharger turbine, Energy Conversion and Management 81 (2014) 270 - 281. doi:http://dx.doi.org/10.1016/j.enconman.2014.01.043.

[7] M. Chiong, S. Rajoo, A. Romagnoli, A. Costall, R. Martinez-Botas, Nonadiabatic pressure loss boundary condition for modelling turbocharger turbine pulsating flow, Energy Conversion and Management 93 (2015) 267 281. doi:http://dx.doi.org/10.1016/j.enconman.2014.12.058.

[8] J. Macek, Z. Zak, O. Vitek, Physical model of a twin-scroll turbine with unsteady flow, SAE Technical Paper 2015-01-1718doi:10.4271/2015-01-1718.

[9] X. Fang, Q. Dai, Modeling of turbine mass flow rate performances using the taylor expansion, Applied Thermal Engineering 30 (13) (2010) 1824 1831. doi:http://dx.doi.org/10.1016/j.applthermaleng.2010.04.016.

[10] M. Gugau, H. Roclawski, On the design and matching of turbocharger single scroll turbines for pass car gasoline engines, J. Eng. Gas Turbines Power 136 (12). doi:10.1115/1.4027710.

[11] D. Palfreyman, R. Martinez-Botas, The pulsating flow field in a mixed flow turbocharger turbine: an experimental and computational study, Proceedings of the ASME Turbo Expo 2004 (2004) 697-708.

[12] M. Padzillah, S. Rajoo, R. Martinez-Botas, Influence of speed and frequency towards the automotive turbocharger turbine performance under pulsating flow conditions, Energy Conversion and Management 80 (2014) 416 - 428. doi:http://dx.doi.org/10.1016/j.enconman.2014.01.047.

[13] A. Romagnoli, R. Martinez-Botas, Performance prediction of a nozzled and nozzleless mixed-flow turbine in steady conditions, International Journal of Mechanical Sciences 53 (8) (2011) 557 - 574. doi:http://dx.doi.org/10.1016/j.ijmecsci.2011.05.003.

[14] F. Payri, J. R. Serrano, P. Fajardo, M. A. Reyes-Belmonte, R. GozalboBelles, A physically based methodology to extrapolate performance maps 
of radial turbines, Energy Conversion and Management 55 (0) (2012) 149 $-163$.

[15] N. Baines, A meanline prediction method for radial turbine efficiency, In: 6th International conference on turbocharging and air management systems. Proc. IMechE C554-6 (1998) 315-325.

[16] R. Dambach, H. Hodson, Tip leakage flow: a comparison between small axial and radial turbines, IMechE Sym S 767.

[17] L. Eriksson, Modeling and control of turbocharged SI and DI engines, Oil Gas Sci Technology-Revue de l'IFP 62(4) (2007) 523-538.

[18] M. Canova, Development and validation of a control-oriented library for the simulation of automotive engines, Int J Engine Res 5(3) (2004) 219-228.

[19] S. Zhu, K. Deng, S. Liu, Modeling and extrapolating mass flow characteristics of a radial turbocharger turbine, Energy 87 (2015) 628 - 637. doi:http://dx.doi.org/10.1016/j.energy.2015.05.032.

[20] J. R. Serrano, A. O. Tiseira, L. M. García-Cuevas, L. B. Inhestern, H. Tartoussi, Radial turbine performance measurement under extreme off-design conditions, Submitted to Energy.

[21] J. Galindo, J. R. Serrano, C. Guardiola, C. Cervelló, Surge limit definition in a specific test bench for the characterization of automotive turbochargers, Experimental Thermal and Fluid Science 30 (5) (2006) 449 - 462. doi:http://dx.doi.org/10.1016/j.expthermflusci.2005.06.002.

[22] R. Bontempo, M. Cardone, M. Manna, G. Vorraro, Steady and unsteady experimental analysis of a turbocharger for automotive applications, Energy Conversion and Management 99 (2015) 72 - 80. doi:http://dx.doi.org/10.1016/j.enconman.2015.04.025.

[23] J. R. Serrano, P. Olmeda, F. J. Arnau, A. Dombrovsky, L. Smith, Analysis and methodology to characterize heat transfer phenomena in automotive 
turbochargers, ASME. J. Eng. Gas Turbines Power 137(2) (2014) 021901021901-11. doi:http://dx.doi.org/10.1115/1.4028261.

[24] J. R. Serrano, P. Olmeda, F. J. Arnau, M. A. Reyes-Belmonte, H. Tartoussi, A study on the internal convection in small turbochargers. proposal ofheat transfer convective coefficients, Applied Thermal Engineering 89 (2015) 587 - 599. doi:http://dx.doi.org/10.1016/j.applthermaleng.2015.06.053.

[25] J. R. Serrano, P. Olmeda, A. Páez, F. Vidal, An experimental procedure to determine heat transfer properties of turbochargers, Measurement Science and Technology 21 (3) (2010) 035109.

[26] P. Olmeda, A. Tiseira, V. Dolz, L. Garca-Cuevas, Uncertainties in power computations in a turbocharger test bench, Measurement 59 (2015) 363 371. doi:http://dx.doi.org/10.1016/j.measurement.2014.09.055.

[27] L. García-Cuevas, Experiments and modelling of automotive turbochargers under unsteady conditions, Ph.D. thesis, Universitat Politècnica de València (2014).

[28] F. S. Ahmed, S. Laghrouche, A. Mehmood, M. E. Bagdouri, Estimation of exhaust gas aerodynamic force on the variable geometry turbocharger actuator: 1D flow model approach, Energy Conversion and Management 84 (2014) 436 - 447. doi:http://dx.doi.org/10.1016/j.enconman.2014.03.080.

[29] M. Reyes-Belmonte, Contribution to the experimental characterization and 1-D modelling of turbochargers for IC engines, Ph.D. thesis, Universitat Politècnica de València (2013).

[30] G. Besagni, R. Mereu, P. Chiesa, F. Inzoli, An Integrated Lumped Parameter-CFD approach for off-design ejector performance evaluation, Energy Conversion and Management 105 (2015) 697 - 715. doi:http://dx.doi.org/10.1016/j.enconman.2015.08.029. 